\title{
Optical Analytical Technique for Carbonaceous Particles Using Laser-Induced Electro-Avalanche Fluorescence and Laser-Induced Incandescence
}

\author{
Satoshi Ikezawa*, Muneaki Wakamatsu ${ }^{1}$ and Toshitsugu Ueda \\ Graduate School of Information, Production and Systems, Waseda University, \\ 2-7 Hibikino, Wakamatsu-ku, Kitakyushu-shi, Fukuoka 808-0135, Japan \\ 'Yokogawa Electric Corporation, \\ 2-9-32 Naka-cho, Musashino-shi, Tokyo 180-8750, Japan \\ ${ }^{2}$ Graduate School of Information, Production and Systems, Waseda University, \\ 2-7 Hibikino, Wakamatsu-ku, Kitakyushu-shi, Fukuoka 808-0135, Japan
}

(Received October 9, 2012; accepted November 12, 2012)

Key words: laser, LIBS, LII, SPM, nanoparticles

This report describes an optical sensing system for fine particle detection using a combination of two techniques: laser-induced breakdown spectroscopy (LIBS) and laserinduced incandescence (LII). We have improved laser measurement systems applied for small-particle analysis. We have determined elemental composition and density of particles using LIBS and have been able to measure particle size using LII. Controlling the power density of the light source of the present system allowed switching from LIBS to LII. LII temporal analysis was conducted using a streak camera, which was also used for LIBS analysis. The LII technique allows in situ measurement of the average primary particle size of nanoscale soot particles.

\section{Introduction}

Recent rapid worldwide economic growth and industrialization have increased awareness of environmental issues such as fossil fuel emissions from factories, power plants, and automobiles. Diesel engines are known to be more fuel-efficient than gasoline engines; furthermore, electronically controlled common rail injection contributes to the clean burning of fuel. As a result, cleaner burning engines often produce smaller specks of soot - nanosize particles - as a by-product. It is also well known that the inhalation of fine particulate matter causes a range of health problems: ${ }^{(1-4)}$ particles that are smaller than $2.5 \mu \mathrm{m}$ in size $\left(\mathrm{PM}_{2.5}\right)$ can penetrate into the gas-exchange

*Corresponding author: e-mail: ikezawa@y.fuji.waseda.jp 
region of the lungs. Using existing technologies, it is difficult to analyze (in real time) the size and composition of fine particles over a broad range of conformational space in the atmosphere.

Laser-induced breakdown spectroscopy (LIBS) is a useful tool for determining the elemental composition of various materials and does not require any preprocessing. Specifically, LIBS is sensitive to nanoscale particulates. However, it is not possible to obtain particle size information using the LIBS technique alone. Conventionally, optical microscopes or scanning electrical microscopes (SEMs) have been used to observe the size and shape of particles; a particle size classification apparatus with a laser has traditionally been used to monitor the size and distribution of suspended particles.

However, such conventional methods do not allow the real-time monitoring of the size of nanoscale particles such as soot. Previously, we used an LIBS system combined with a scanning mobility particle sizer (SMPS) for particle size measurement. ${ }^{(5)}$ This combined system can reveal the significance of the aggregate nature of soot via the interpretation of size and volume fraction measurements obtained with an SMPS, but the accuracy of primary particle size measurements must be verified by another method.

In this study, we apply the laser-induced incandescence (LII) technique with LIBS. The average primary particle size is determined through the use of simulation models in conjunction with the LII technique. The simulation method adopted in this experiment has undergone considerable change and development as a result of the following experiments.

In 1977, Eckbreth recognized the LII concept while working with Raman spectroscopy in flames and becoming troubled by the presence of soot. ${ }^{(6)}$ He was able to relate the time dependence of the interference to laser particulate heating. This work was subsequently developed by Melton and other researchers. ${ }^{(7,8)}$

The LII technique adopted in this study is based on these earlier experiments, and the decay simulation model applied is based on one of the most detailed studies available, that provided by Michelsen. ${ }^{(9)}$ In order to utilize this approach, one must first show good agreement between simulated and measured laser profiles. The laser intensity profile plays an important role in the theoretical estimation of the energy absorption rate. We demonstrate that an accurate laser intensity profile can be obtained using the streak camera that was used for LIBS in the preliminary experiment. Furthermore, when Michelsen's model is used for the determination of the primary particle size, our approach results in a ratio of LII signals that is in qualitative agreement with the theoretical model. One major advantage of our LII technique is that the laser profile and particle cooling behavior over the full extent of the decay curve can be obtained easily.

\section{Basic Principles}

\subsection{Laser-induced breakdown spectroscopy}

LIBS is considered to be in the same category as atomic emission spectroscopy (AES), which includes many well-known methods of vaporization and excitation: arc/spark spectrometry, direct-coupled plasma (DCP) spectrometry, inductively coupled plasma (ICP) spectrometry, microwave-induced plasma (MIP) spectrometry, and laser ablation 
inductively coupled plasma mass spectrometry (LA-ICP-MS). The basic steps involved in AES can be summarized as follows: (1) vaporization of the sample to produce free atomic species, (2) excitation of atoms, (3) detection of emitted light, (4) calibration of intensity to concentration relationship, and (5) determination of quantitative information. The relationship between free electrons and AES is based on electron orbit and quantum number. According to Bohr's theory of atomic structure, light with frequency $v$ should be considered as a photon with energy $h v$ (Planck's constant $h \approx 6.63 \times 10^{-34} \mathrm{~J} \cdot \mathrm{s}$ ). The transition energy of an electron stationary state from $E_{n}$ to $E_{n^{\prime}}$ is determined by

$$
v=\frac{E_{n}-E_{n^{\prime}}}{h}=\frac{2 \pi^{2} \kappa^{2} m e^{4}}{h^{3}}\left(\frac{1}{n^{\prime 2}}-\frac{1}{n^{2}}\right)
$$

where $\kappa$ is Coulomb's constant $\left(\kappa=1 / 4 \pi \varepsilon_{0} \approx 8.99 \mathrm{~N} \cdot \mathrm{m}^{2} \cdot \mathrm{C}^{2}\right), m$ is electron mass $(m \approx 9.11$ $\left.\times 10^{-31} \mathrm{~kg}\right)$, and $e$ is a quantum of electricity $\left(e \approx 1.60 \times 10^{-19} \mathrm{C}\right)$.

As presented above, the electron orbit is considered to be a circle. When the electron orbit is regarded as elliptical, a radial component $r$ and an azimuthal component are required. Two quantum conditions are required, corresponding to these two components: the principal quantum number $n$, which corresponds to the radial component in the elliptical orbit; and the azimuthal quantum number $l$, which corresponds to the azimuthal component. The relationship between $n$ and $l$ is described by

$$
l=0,1,2, \ldots, n-1 .
$$

The quantum number $n$ denotes the variety in orbital size, while the azimuthal quantum number $l$ represents its ellipticity. Thus, $n$ corresponds physically to the kinetic energy of an electron and $l$ corresponds to its angular momentum. The electron energy is given by

$$
E_{n}=-\frac{2 \pi^{2} \kappa_{0}^{2} m e^{4}}{h^{2}} \cdot \frac{1}{n^{2}}(n=1,2, \ldots)
$$

To describe the electron orbit three-dimensionally, a third magnetic quantum number $m_{l}$, must be introduced. The range of $m_{l}$ is related to the azimuthal quantum number $l$, and is given by

$$
-l \leq m_{l} \leq l
$$

The existence of a third quantum condition implies that the direction of the electron orbital plane is quantum restricted. The direction of the plane is defined as being between the direction of the magnetic field and a normal vector in the orbital plane. Thus, the quantum number $m_{l}$ is referred to as the "magnetic quantum number." When the magnetic field exists, the variation of electron energy depends on the value of $m_{l}$. Finally, there is a fourth quantum number: the spin quantum number $m_{\mathrm{s}}$ parameterizes the intrinsic angular momentum of an electron in a manner corresponding to its right-hand or 
left-hand rotation in classical atomic theory. The spin quantum number $m_{\mathrm{s}}$ can have only two values,

$$
m_{\mathrm{s}}= \pm \frac{1}{2}
$$

The electron configuration in multielectron atoms obeys the Pauli exclusion principle: no two identical fermions (particles with half-integer spin) may occupy the same quantum state simultaneously.

A common way to name states in atomic physics is to use spectroscopic notation; this is a standard way to write down the angular momentum quantum numbers of a state as follows.

$$
N^{2 S+1} L_{J}
$$

where $N$ is the principal quantum number ( $N$ is often omitted), $S$ is the total spin quantum number, $2 S+1$ is the number of spin states, $L$ refers to the orbital angular momentum quantum number $l, l$ is written as $S, P, D, F, G, H, I, \ldots$ (for $l=0,1,2,3,4,5,6, \ldots$ ), and $J$ is the total angular momentum quantum number.

One example is a single-electron transition, which we find in carbon emission at wavelength $\lambda=247.856 \mathrm{~nm}$ :

$$
\text { [Upper Level: } \left.\left.2 \mathrm{~s}^{2} 2 \mathrm{p} 3 \mathrm{~s},{ }^{1} \mathrm{P}^{\mathrm{o}}{ }_{1}\right] \rightarrow \text { [Lower Level: } 2 \mathrm{~s}^{2} 2 \mathrm{p}^{2},{ }^{1} \mathrm{~S}_{0}\right]
$$

where the first terms in brackets represent the electron shell structure (see Table 1) and the second terms represent the standard spectroscopic notation described above.

\begin{tabular}{|c|c|c|c|c|c|}
\hline \multirow{2}{*}{ Major shell } & \multicolumn{2}{|c|}{ Quantum number } & \multirow{2}{*}{ Subshell } & \multirow{2}{*}{$\begin{array}{l}\text { Number of } \\
\text { orbits (ml) }\end{array}$} & \multirow{2}{*}{$\begin{array}{l}\text { Number of } \\
\text { electrons } \\
\text { (ms) }\end{array}$} \\
\hline & $n$ & $l$ & & & \\
\hline $\mathrm{K}$ & 1 & 0 & $1 \mathrm{~s}$ & 1 & 2 \\
\hline \multirow{2}{*}{$\mathrm{L}$} & \multirow{2}{*}{2} & 0 & $2 \mathrm{~s}$ & 1 & 2 \\
\hline & & 1 & $2 \mathrm{p}$ & 3 & 6 \\
\hline \multirow{3}{*}{ M } & \multirow{3}{*}{3} & 0 & $3 \mathrm{~s}$ & 1 & 2 \\
\hline & & 1 & $3 p$ & 3 & 6 \\
\hline & & 2 & $3 d$ & 5 & 10 \\
\hline \multirow{4}{*}{$\mathrm{N}$} & \multirow{4}{*}{4} & 0 & $4 s$ & 1 & 2 \\
\hline & & 1 & $4 p$ & 3 & 6 \\
\hline & & 2 & $4 d$ & 5 & 10 \\
\hline & & 3 & $4 \mathrm{f}$ & 7 & 14 \\
\hline
\end{tabular}

Table 1

Electron shell structure. 
In the laser-induced breakdown process for wide-bandgap materials, an electron raised from ground state to the conduction band behaves as a free electron. There are three ways to raise an electron to the conduction band: (1) excitation by incident photon energy, (2) excitation from the defect energy levels, and (3) excitation by a multiphoton process. In case (1), the wavelength of the laser must correspond to the excitation energy level. For LIBS on materials with a wide-bandgap structure, a laser with higher photon energy (i.e., shorter wavelength) is required. In case (2), materials typically contain traces of impurities or exhibit a slightly defective structure. Even slight defects are sufficient to generate laser-induced plasma. The defective structure not only contributes to the excitation of one electron from its defect energy level to the conduction band, which corresponds to the laser wavelength, but it also produces an electron avalanche. An electron avalanche is a phenomenon in which a number of electrons raised to the conduction band are rapidly accelerated by the laser electric field, ionizing the atoms by collision, thereby forming new electrons to undergo the same process in successive cycles. Through an electron avalanche, the electron density reaches the dielectric breakdown level. The rate of dielectric breakdown for wide-bandgap materials is related to the impurity concentration. ${ }^{(10,11)}$ In case (3), the interaction is based on elementary single-photon absorption and emission events. ${ }^{(12)}$ Perturbation theory approximates an elementary event involving the simultaneous participation of many photons. A photon transition may be considered as a transition that passes, in its upper stages, through intermediate states of the system. First, one photon is absorbed and the system passes from the ground state to the first upper state; then, a second photon is absorbed and the system passes into its second upper state, and so on. Finally, as a result of elementary single-photon events, the system passes into the final state. The concept of multiphoton processes was developed in quantum field theory to describe the interaction of radiation with matter. However, observing multiphoton processes is difficult because of their extraordinarily low probability compared with single-photon processes. Multiphoton processes have become increasingly important with the application of high-intensity lasers. On the basis of the laser-induced plasma produced by a short-pulsed laser with high peak intensity, the photon density is sufficient to induce a multiphoton process. Using laser sources with high radiation power density $\left(10^{15} \mathrm{~W} / \mathrm{cm}^{2}\right)$, the probability of multiphoton processes becomes comparable to that of single-photon transitions.

\subsection{Laser-induced incandescence}

LII is a technique in which a high-power laser beam is used to superheat primary soot particles up to 5000 to $10000 \mathrm{~K}$. The resulting incandescence is collected with a timeresolved optical device for capturing the time-dependent signal. In the present study, a short laser pulse ( $8 \mathrm{~ns}$ ) is followed by a period of incandescence that lasts 200 to 1000 ns. Because the smaller particles decay faster than larger particles, the characteristics of the time decay can be used to extract information about size distributions. For volume fraction imaging, it is possible to operate in a saturated regime for which the LII signal is almost independent of laser energy and is only dependent upon the particle density multiplied by the particle diameter to the third power. For the LII calculation, a decay simulation model based on that of Michelsen was used.(9) According to this model, the energy balance for the interaction of a particle with a laser is given by 


$$
Q_{\text {Int }}=Q_{\text {abs }}-Q_{\text {rad }}-Q_{\text {cond }}-Q_{\text {sub }}+Q_{\text {ann }}+Q_{\text {ox }},
$$

where $Q_{\text {Int }}$ represents the sensible energy stored in a particle, $Q_{\mathrm{abs}}$ is the rate of laser energy absorption, $Q_{\text {rad }}$ is the rate of radiation by blackbody emission, $Q_{\text {cond }}$ represents the rate of energy dissipation by conduction, $Q_{\text {sub }}$ represents the rate of energy loss by the sublimation of carbon clusters (and also accounts for the energy consumed during the photodesorption of the annealed particles to form small carbon clusters), $Q_{\text {ann }}$ represents the rate of energy production by particle annealing, and $Q_{\mathrm{ox}}$ represents the rate of energy generation by oxidation. Each term in this energy flow rate equation is accounted for by the laser beam temporal intensity profile, the time dependence of the particle temperature, and the initial state of the particle. The time-derivative term of the particle temperature yields

$$
\frac{\mathrm{d} T}{\mathrm{~d} t}=\frac{6}{\pi D^{3} \rho_{S} c_{S}}\left(Q_{\mathrm{abs}}-Q_{\mathrm{rad}}-Q_{\mathrm{cond}}-Q_{\mathrm{sub}}+Q_{\mathrm{ann}}+Q_{\mathrm{ox}}\right)
$$

where $T$ is the particle temperature, $D$ is the primary particle diameter, $\rho_{S}$ is the density of the particle, and $c_{S}$ is the specific heat of solid carbon. From Planck's equation for a blackbody, the LII signal at wavelength $\lambda^{\prime}$ is given by

$$
S=\Omega \pi D^{2} \int_{\lambda} \varepsilon_{\lambda} \frac{2 \pi h c^{2}}{\lambda^{\prime 5}\left[\exp \left(\frac{h c}{\lambda^{\prime} k_{\mathrm{B}} T}\right)-1\right]}-\Sigma_{\lambda}\left(\lambda^{\prime}\right) \mathrm{d} \lambda^{\prime},
$$

where $\Omega$ is the normalization constant, $\varepsilon_{\lambda}$ is the emissivity at wavelength $\lambda$ for a Rayleigh particle, $h$ is Planck's constant, $c$ is the speed of light, $k_{\mathrm{B}}$ is the Boltzmann constant, and $\Sigma_{\lambda}$ is accounted for by including it in the integration of the Planck function over wavelength. In the differential equation given by eq. (9), each term of the energy flow ratio is calculated from the laser beam intensity profile that was obtained from actual measurements.

The energy absorption rate was calculated as

$$
Q_{\mathrm{abs}}=\frac{\pi^{2} D^{3} E(m)}{\lambda} q(t)
$$

where $D$ is the primary particle diameter and $\lambda$ is the wavelength of the laser. The intensity profile $q(t)$ was obtained experimentally. $E(m)$ is a function of the complex refractive index and is expressed as

$$
E(m)=\frac{6 n_{m} k_{m}}{\left(n_{m}^{2}-k_{m}^{2}+2\right)^{2}+4 n_{m}^{2} k_{m}^{2}} .
$$

The refractive index of soot, $m=n_{m}-k_{m} i$, was given by the laser wavelength: 1064 $\mathrm{nm}$ for $n_{m}=1.63$ and $k_{m}=0.7 .^{(13-16)}$ This profile was obtained by substituting the laser 
profile into eq. (11). The radiation rate was calculated as follows:

$$
Q_{\mathrm{rad}}=\frac{199 \pi^{3} D^{3}\left(k_{\mathrm{B}} T\right)^{5} E(m)}{h(h c)^{3}}
$$

where $k_{\mathrm{B}}$ is the Boltzmann constant, $h$ is Planck's constant, and $c$ is the speed of light. The time profile of the rate of energy loss due to radiation from the particle was obtained by successive iterations from the initial value of the temperature $\left(T_{0}=1060[\mathrm{~K}]\right)$. The thermal conductivity of soot was calculated as

$$
Q_{\mathrm{cond}}=\frac{2 \kappa_{a} \pi D^{2}}{(D+G L)}\left(T-T_{0}\right)
$$

where $\kappa_{a}$ is the thermal conductivity of the surrounding gas $\left(\kappa_{a}=1.0811 \times 10^{-4}+5.1519\right.$ $\times 10^{-7} T_{0}$ was used in this study), and $L$ is the mean free path $\left(L=2.24 \times 10^{-8} T_{0}[\mathrm{~cm} / \mathrm{K}]\right)$. $G$ is the heat transfer factor ${ }^{(7,17)}$ given by

$$
G=\frac{8 f}{\alpha_{T}(\gamma+1)}
$$

where $f$ is the Eucken factor $(f=(9 \gamma-5) / 4), \gamma$ is the heat capacity ratio $(\gamma=1.3),{ }^{(9,18-20)}$ and $\alpha_{T}$ is the thermal accommodation coefficient of the ambient combustion gases with the surface $\left(\alpha_{T}=0.3\right) \cdot{ }^{(9)}$ Sublimation at higher temperatures during laser irradiation, producing gas-phase carbon atom clusters, was calculated as

$$
Q_{\text {sub }}=\sum_{j=1}^{10} \frac{1}{W_{j}}\left(\frac{\mathrm{d} M}{\mathrm{~d} t}\right)_{j}\left[\frac{\Delta H_{j}\left(P_{\mathrm{sat}}^{\mathrm{C}_{j}}-P_{\mathrm{phot}}^{\mathrm{C}_{j}}\right)+\Delta H_{\lambda \mathrm{s}} P_{\lambda \mathrm{s}}+\Delta H_{\mathrm{diss}} P_{\mathrm{diss}}+\Delta H_{\lambda \mathrm{a}} P_{\lambda \mathrm{a}}}{P_{\text {sat }}^{\mathrm{C}_{j}}}\right],
$$

where $W_{j}$ is the molecular weight of a carbon cluster comprising 1-10 carbon atoms with vapor $\left(W_{j}=j \times 12.011 \mathrm{~g} / \mathrm{mol}\right)$, and the summation was assumed to be the contribution, respectively, to $Q_{\text {sub }}$ of $\mathrm{C}_{1}$ to $\mathrm{C}_{10}$ desorbed species with vaporized molecular weights from $W_{1}$ to $W_{10} . \Delta H_{j}$ is the enthalpy of the formation of carbon vapor species $\mathrm{C}_{j}$ (given by eq. (43)), and $P_{\text {sat }}^{\mathrm{C}_{j}}$ is the saturation partial pressure of $\mathrm{C}_{j}$ given by eqs. (17) and (18):

$$
\begin{gathered}
P_{\text {sat }}^{\mathrm{C}_{j}}=P_{\text {ref }} \exp \left(\frac{\Delta S_{j}}{R}-\frac{\Delta H_{j}}{R T}\right) \text { if } P_{\text {equil }}^{\mathrm{C}_{j}} \geq P_{\text {phot }}^{\mathrm{C}_{j}}, \\
P_{\text {sat }}^{\mathrm{C}_{j}}=P_{\lambda \mathrm{s}}+P_{\text {diss }}+P_{\lambda \mathrm{a}} \text { if } P_{\text {equil }}^{\mathrm{C}_{j}} \leq P_{\text {phot }}^{\mathrm{C}_{j}}, \\
P_{\text {equil }}^{\mathrm{C}_{j}}=P_{\text {ref }} \exp \left(\frac{\Delta S_{j}}{R}-\frac{\Delta H_{j}}{R T}\right)
\end{gathered}
$$




$$
P_{\text {phot }}^{\mathrm{C}_{j}}=P_{\lambda \mathrm{s}}+P_{\text {diss }}+P_{\lambda \mathrm{a}} \text {. }
$$

Equation (19) is the so-called Clausius-Clapeyron equation, which gives $P_{\text {equil }}^{\mathrm{C}_{j}}$ as the thermal equilibrium partial pressure of $\mathrm{C}_{j}(\mathrm{~atm}) . \quad P_{\text {ref }}$ is the reference pressure $\left(P_{\text {ref }}\right.$ $=1 \mathrm{~atm}) . \Delta S_{j}$ and $\Delta H_{j}$ are obtained from eqs. (42) and (43), respectively. $P_{\text {phot }}^{\mathrm{C}_{j}}$ is the instantaneous partial pressure of $\mathrm{C}_{j}$ from the photodesorption of the particle. $P_{\lambda \mathrm{s}}$ in eqs. (16) and (20) is the effective pressure calculated from the rate of nonthermal photodesorption from the unannealed particle:

$$
P_{\lambda \mathrm{s}}=\frac{k_{\mathrm{p}} T k_{\lambda \mathrm{s}}}{\pi D^{2} \alpha_{j} U_{j}}
$$

where $k_{\mathrm{p}}$ is the Boltzmann constant in effective pressure units $\left(1.3626 \times 10^{-22} \mathrm{~atm} \mathrm{~cm}^{3} / \mathrm{K}\right)$. $\alpha_{j}$ is the mass accommodation coefficient of vaporized species; it was assumed that $\alpha_{j}=$ 0.5 (for $j=1$ and 2), $\alpha_{j}=0.1$ (for $j=3$ ), and $\alpha_{j}=1.0 \times 10^{-4}$ (for $j=4$ to 10$){ }^{(9,34)} U_{j}$ is the mean velocity away from the particle surface given by $U_{j}=\left(R_{\mathrm{m}} T / 2 \pi W_{j}\right)^{1 / 2}$, and $R_{m}$ is the universal gas constant in effective mass units $\left(8.3145 \times 10^{7}\left[\mathrm{~g} \cdot \mathrm{cm}^{2} / \mathrm{mol} \cdot \mathrm{K} \cdot \mathrm{s}^{2}\right]\right) . \quad k_{\lambda \mathrm{s}}$ is the rate constant for the unannealed particle, given by

$$
k_{\lambda \mathrm{s}}=\frac{\sigma_{\lambda \mathrm{s}} \pi D^{3} N_{\mathrm{ss}}\left(1-X_{\mathrm{ann}}-X_{\mathrm{melt}}\right)}{6} \times\left\{1-\exp \left[-B_{\lambda \mathrm{s}} F^{n} q_{\mathrm{exp}}(t)^{2}\right]\right\},
$$

where $\sigma_{\lambda \mathrm{s}}$ is the cross section for the removal of carbon clusters $\mathrm{C}_{1}-\mathrm{C}_{3}$ from the unannealed particle by a two-photon nonthermal process $\left(1 \times 10^{16} \mathrm{~cm}^{-1} \cdot \mathrm{s}^{-1}\right)^{(9)}$ and $N_{\mathrm{ss}}$ is the density of carbon atoms on the surface of the unannealed particle (estimated to be $\left.2.8 \times 10^{15} \mathrm{~cm}^{-2}\right){ }^{(9)} X_{\text {ann }}$ is the mass fraction annealed according to eq. (32), and was estimated to be $1.0 \times 10^{-6}$. $X_{\text {melt }}$ is the mass fraction melted, and $X_{\text {melt }}$ was also estimated to be $1.0 \times 10^{-6}$. When the maximum of $q_{\text {exp }}(t)$ is normalized to one, the saturation is given by $B_{\lambda \mathrm{s}}=0.4 \mathrm{~cm}^{4} / \mathrm{J}^{2} . F$ is the laser fluence, equal to $q(t)$ integrated over the pulse duration $\left(\mathrm{J} / \mathrm{cm}^{2}\right)$.

$P_{\text {diss }}$ in eqs. (16) and (20) is the effective pressure calculated from the rate of thermal photodesorption from the annealed particle (atm), given by

$$
P_{\text {diss }}=\frac{k_{\mathrm{p}} T k_{\mathrm{diss}} X_{\mathrm{ann}} N_{\mathrm{p}}}{2 \pi D^{2} \alpha_{j} U_{j}}
$$

where $k_{\text {diss }}$ is the rate constant for the pyrolysis of the annealed particle $(1 / \mathrm{s})$, given by

$$
k_{\text {diss }}=A_{\text {diss }} \exp \left(\frac{-E_{\text {diss }}}{R T}\right)
$$

where $A_{\text {diss }}$ is the factor for the annealed particle $\left(1 \times 10^{18} \mathrm{~s}^{-1}\right)$, and $E_{\text {diss }}$ is the activation energy for the pyrolysis of the annealed particle to produce $\mathrm{C}_{2}\left(9.6 \times 10^{5} \mathrm{~J} / \mathrm{mole}\right) \cdot{ }^{(9)} R$ is 
the universal gas constant $(8.3145 \mathrm{~J} / \mathrm{mol} \cdot \mathrm{K})$. All other parameters in eq. (23) are equal to those in eqs. (21) and (22).

$P_{\lambda \mathrm{a}}$ in eqs. (16) and (20) is the effective pressure calculated from the rate of nonthermal photodesorption from the annealed particle (atm), given by

$$
P_{\lambda \mathrm{a}}=\frac{k_{\mathrm{p}} T k_{\lambda \mathrm{a}}}{\pi D^{2} \alpha_{j} U_{j}}
$$

where $k_{\mathrm{p}}, \alpha_{j}$ and $U_{j}$ have the same values as in the calculation of $P_{\lambda \mathrm{s}}$ (eq. 21). $k_{\lambda \mathrm{a}}$ is given by

$$
k_{\lambda \mathrm{a}}=\frac{\sigma_{\lambda \mathrm{a}} \pi D^{3} N_{\mathrm{sa}} X_{\mathrm{ann}}}{6} \times\left\{1-\exp \left[-B_{\lambda \mathrm{a}} F^{n} q_{\mathrm{exp}}(t)^{n}\right]\right\}
$$

where $\sigma_{\lambda \mathrm{a}}$ is the cross section for the removal of carbon clusters $\mathrm{C}_{2}$ from the annealed particle by a two-photon nonthermal process $\left(1 \times 10^{16} \mathrm{~cm}^{-1} \cdot \mathrm{s}^{-1}\right),{ }^{(9)} N_{\mathrm{sa}}$ is the density of carbon atoms on the surface of the annealed particle (estimated to be $3.8 \times 10^{15} \mathrm{~cm}^{-2}$ ), ${ }^{(9)}$ and $X_{\text {ann }}$ is the mass fraction annealed according to eq. (32); $X_{\text {ann }}$ was estimated to be 1.0 $\times 10^{-6}$. When the maximum of $q_{\exp }(t)$ is normalized to one, the saturation coefficient for the removal of carbon clusters $\mathrm{C}_{2}$ from the annealed particle by a two-photon nonthermal process is given by $B_{\lambda \mathrm{a}}=0.9 \mathrm{~cm}^{4} / \mathrm{J}^{2} . F$ is the laser fluence, equal to $q(t)$ integrated over the pulse duration $\left(\mathrm{J} / \mathrm{cm}^{2}\right)$.

$\Delta H_{\lambda s}$ is the energy required to remove carbon clusters from the unannealed particle with no thermal photodesorption $\left(\Delta H_{\lambda \mathrm{s}}=7.2 \times 10^{5} \mathrm{~J} / \mathrm{mol}\right.$ for $\mathrm{C}_{1}, \Delta H_{\lambda \mathrm{s}}=3.4 \times 10^{5} \mathrm{~J} / \mathrm{mol}$ for $\mathrm{C}_{2}, \Delta H_{\lambda \mathrm{s}}=7.4 \times 10^{4} \mathrm{~J} / \mathrm{mol}$ for $\left.\mathrm{C}_{3}\right)^{(9)}$ and $\Delta H_{\text {diss }}$ is the estimated enthalpy of pyrolysis $\left(\Delta H_{\text {diss }}=8.0 \times 10^{5} \mathrm{~J} / \mathrm{mol}\right)$ derived from the calculation of the enthalpy of $\mathrm{C}_{2}$ in Table 2 . $\Delta H_{\lambda \mathrm{a}}$ is the energy required to remove carbon clusters from the annealed particle with no

Table 2

Coefficients for entropies [eq. (42)] and enthalpies [eq. (43)] of formation of carbon clusters.

\begin{tabular}{lccccccc}
\hline $\begin{array}{l}\text { Carbon } \\
\text { cluster }\end{array}$ & $\begin{array}{c}b_{S 0} \\
(\mathrm{~J} / \mathrm{mol} \mathrm{K})\end{array}$ & $\begin{array}{c}b_{S 1} \\
\left(10^{-3} \mathrm{~J} / \mathrm{mol} \mathrm{K}\right)\end{array}$ & $\begin{array}{c}b_{S 2} \\
\left(10^{-7} \mathrm{~J} / \mathrm{mol} \mathrm{K}\right)\end{array}$ & $\begin{array}{c}b_{H 0} \\
\left(10^{5} \mathrm{~J} / \mathrm{mol} \mathrm{K}\right)\end{array}$ & $\begin{array}{c}b_{H 1} \\
(\mathrm{~J} / \mathrm{mol} \mathrm{K})\end{array}$ & $\begin{array}{c}b_{H 2} \\
\left(10^{-3} \mathrm{~J} / \mathrm{mol} \mathrm{K}\right)\end{array}$ & $\begin{array}{c}\text { Sublimation } \\
\text { temperature } \\
(\mathrm{K})\end{array}$ \\
\hline $\mathrm{C}_{1}$ & 160.01 & -1.553 & 0 & 7.266 & -5.111 & 0 & 4585 \\
$\mathrm{C}_{2}$ & 202.62 & -7.584 & 5.246 & 8.545 & -12.326 & 0 & 4419 \\
$\mathrm{C}_{3}$ & 225.12 & -16.131 & 10.900 & 8.443 & -26.921 & 0 & 4073 \\
$\mathrm{C}_{4}$ & 217.42 & -9.619 & 4.089 & 9.811 & -7.787 & -2.114 & 4873 \\
$\mathrm{C}_{5}$ & 227.38 & -10.049 & 3.661 & 9.898 & -7.069 & -2.598 & 4701 \\
$\mathrm{C}_{6}$ & 264.6 & 0 & 0 & 13.56 & 0 & 0 & 5125 \\
$\mathrm{C}_{7}$ & 265.3 & 0 & 0 & 13.45 & 0 & 0 & 5070 \\
$\mathrm{C}_{8}$ & 293.4 & 0 & 0 & 15.80 & 0 & 0 & 5385 \\
$\mathrm{C}_{9}$ & 301.3 & 0 & 0 & 16.11 & 0 & 0 & 5347 \\
$\mathrm{C}_{10}$ & 260.5 & 0 & 0 & 14.99 & 0 & 0 & 5754 \\
\hline
\end{tabular}


thermal photodesorption and is assumed to be the same as that for photodesorption from the unannealed surface; $\Delta H_{\lambda \mathrm{a}}=3.4 \times 10^{5} \mathrm{~J} / \mathrm{mol}$ for $\mathrm{C}_{2}{ }^{\left({ }^{9}\right)}$

A more detailed discussion and the setting of parameters for sublimation theory were presented in Michelsen's work ${ }^{(9)}$ and those of other previous researchers. ${ }^{(21-26)}$

The annealing energy production rate was calculated as

$$
Q_{\text {ann }}=\frac{-\Delta H_{\text {imig }} k_{\text {imig }} N_{\mathrm{d}}-\Delta H_{\mathrm{vmig}} k_{\mathrm{vmig}} N_{\mathrm{d}}}{N_{\mathrm{a}}}
$$

where $\Delta H_{\text {imig }}$ is the estimated enthalpy for interstitial migration $\left(\Delta H_{\text {imig }}=-1.9 \times 10^{4} \mathrm{~J} / \mathrm{mol}\right){ }^{(27)}$ $\Delta H_{\text {vmig }}$ is the enthalpy for vacancy migration derived from theoretical predictions $\left(\Delta H_{\mathrm{vmig}}\right.$ $\left.=-1.4 \times 10^{5} \mathrm{~J} / \mathrm{mol}\right),{ }^{(28,29)} N_{\mathrm{d}}$ is the number of lattice defects in the particle, and $N_{\mathrm{a}}$ is Avogadro's constant $\left(6.02214 \times 10^{23} \mathrm{~mol}^{-1}\right) . k_{\text {imig }}$ and $k_{\text {vmig }}$ are given by

$$
k_{\text {imig,vmig }}=A_{\text {imig,vmig }} \exp \left(\frac{-E_{\text {imig,vmig }}}{R T}\right)
$$

where $A_{\text {imig }}$ and $A_{\text {vmig }}$ are pre-exponential factors used to calculate the rate constants for interstitial migration and vacancy migration, respectively $\left(A_{\text {imig }}=1 \times 10^{8} \mathrm{~s}^{-1}, A_{\text {vmig }}\right.$ $\left.=1.5 \times 10^{17} \mathrm{~s}^{-1}\right){ }^{(9)} E_{\text {imig }}$ is the activation energy for the annealing rate associated with di-interstitial migration $\left(E_{\text {imig }}=8.3 \times 10^{4} \mathrm{~J} / \mathrm{mol}\right),{ }^{(30)}$ and $E_{\text {vmig }}$ is the activation energy required to attain the appropriate annealing rate for vacancy migration $\left(E_{\mathrm{vmig}}=6.7 \times\right.$ $\left.10^{5} \mathrm{~J} / \mathrm{mol}\right) . \quad R$ is the universal gas constant $(8.3145 \mathrm{~J} / \mathrm{mol} \cdot \mathrm{K}){ }^{(31)}$ The oxidation rate was calculated as

$$
Q_{\mathrm{ox}}=\left(-\Delta H_{\mathrm{ox}}-2 \alpha_{T} C_{\mathrm{P}}^{\mathrm{CO}} T\right) \frac{\pi D^{2} k_{\mathrm{ox}}}{N_{\mathrm{a}}}
$$

where $\Delta H_{\text {ox }}$ is the enthalpy of the reaction $\left(\Delta H_{\text {ox }}=-2.215 \times 10^{5} \mathrm{~J} / \mathrm{mol}\right),{ }^{(32)} \alpha_{T}$ is the thermal accommodation coefficient of the ambient combustion gases with the surface $\left(\alpha_{T}\right.$ $=0.3),{ }^{(9)}$ and $N_{\mathrm{a}}$ is Avogadro's constant. $C_{\mathrm{P}}^{\mathrm{CO}}$ is the molar heat capacity of CO given by the following equation of Fried and Howard: ${ }^{(33)}$

$$
\begin{aligned}
C_{\mathrm{P}}^{\mathrm{CO}}= & \left(\frac{R}{a_{4}}\right)\left\{a_{1}\left(\frac{\theta_{1}}{T}\right)^{2} \exp \left(\frac{\theta_{1}}{T}\right)\left[\exp \left(\frac{\theta_{1}}{T}\right)-1\right]^{-2}\right. \\
& \left.+a_{2}\left(\frac{\theta_{2}}{T}\right)^{2} \exp \left(\frac{\theta_{2}}{T}\right)\left[\exp \left(\frac{\theta_{2}}{T}\right)-1\right]^{-2}+a_{3} T\right\},
\end{aligned}
$$

where $R$ is the general gas constant and the parameters are given as $a_{4}=1, a_{1}=3.494, \theta_{1}=1$, $a_{2}=0.98449, \theta_{2}=3085.1$, and $a_{3}=2.6164 \times 10^{-5}$. ${ }^{(9)} k_{\mathrm{ox}}$ is given by 


$$
k_{\mathrm{ox}}=12 P_{\mathrm{O}_{2}}\left[\frac{k_{a} \chi_{A}}{1+k_{Z} P_{\mathrm{O}_{2}}}+k_{b}\left(1-\chi_{A}\right)\right]\left(1-X_{\mathrm{ann}}\right)+\frac{2.8 Z_{\mathrm{ox}}}{\sqrt{T_{0}}} \exp \left(\frac{-1.4 \times 10^{5}}{R T}\right) X_{\mathrm{ann}},
$$

where $P_{\mathrm{O}_{2}}=P_{0}=1 \mathrm{~atm}, k_{a}=5.0 \times 10^{23} \exp \left(-1.255 \times 10^{5} / R T\right), k_{b}=5.0 \times 10^{21} \exp \left(-6.352 \times 10^{4} /\right.$ $R T), \chi_{A}=1 /\left(1+k_{T} / K_{b} P_{\mathrm{O}_{2}}\right), k_{T}=3.79 \times 10^{27} \exp \left(-4.06 \times 10^{5} / R T\right)$, and $k_{Z}=21.3 \exp (1.713$ $\left.\times 10^{4} / R T\right) .{ }^{(9)} X_{\text {ann }}$ is the mass fraction annealed according to eq. (32), and was estimated to be $1.0 \times 10^{-6}$ for this calculation. $Z_{\text {ox }}$ is the collision rate of the ambient $\mathrm{O}_{2}$ with the particle surface, given by eq. (33), and $Z_{\text {ox }}$ was derived as $3.03 \times 10^{22}\left[1 / \mathrm{s} \mathrm{cm}^{2}\right]$.

$$
X_{\mathrm{ann}}=1-\frac{N_{\mathrm{d}}}{X_{\mathrm{d}} N_{\mathrm{p}}}
$$

where $N_{\mathrm{d}}$ is the number of lattice defects in the particle, $X_{\mathrm{d}}$ is the initial defect density of soot, and $N_{\mathrm{p}}$ is the number of atoms in the particle. $X_{\mathrm{d}}$ and $N_{\mathrm{d}}$ are unknown at this point.

$$
Z_{\mathrm{ox}}=\frac{P_{0}}{k_{\mathrm{p}} T_{0}} \sqrt{\frac{R_{\mathrm{m}} T_{0}}{2 \pi W_{\mathrm{a}}}}
$$

where $P_{0}$ is the ambient pressure, $W_{\mathrm{a}}$ is the average molecular weight (given by $P_{0}=0.209$ [atm], $W_{\mathrm{a}}=31.99[\mathrm{~g} / \mathrm{mol}]$ in this equation), $k_{\mathrm{p}}$ is the Boltzmann constant in effective pressure units $\left(1.3626 \times 10^{-22}[\mathrm{~atm} \mathrm{~cm} / \mathrm{K}]\right)$, and $R_{\mathrm{m}}$ is the universal gas constant in effective mass units $\left(8.3145 \times 10^{7}\left[\mathrm{~g} \mathrm{~cm}^{2} / \mathrm{mol} \mathrm{K} \mathrm{s}^{2}\right]\right)$.

Substituting the initial temperature and initial particle diameter and the above energy flow ratios caused by the laser (Fig. 1) into eq. (9) yields a time profile of particle temperature (Fig. 2). The graph shown in Fig. 1 was created on the basis of the actual

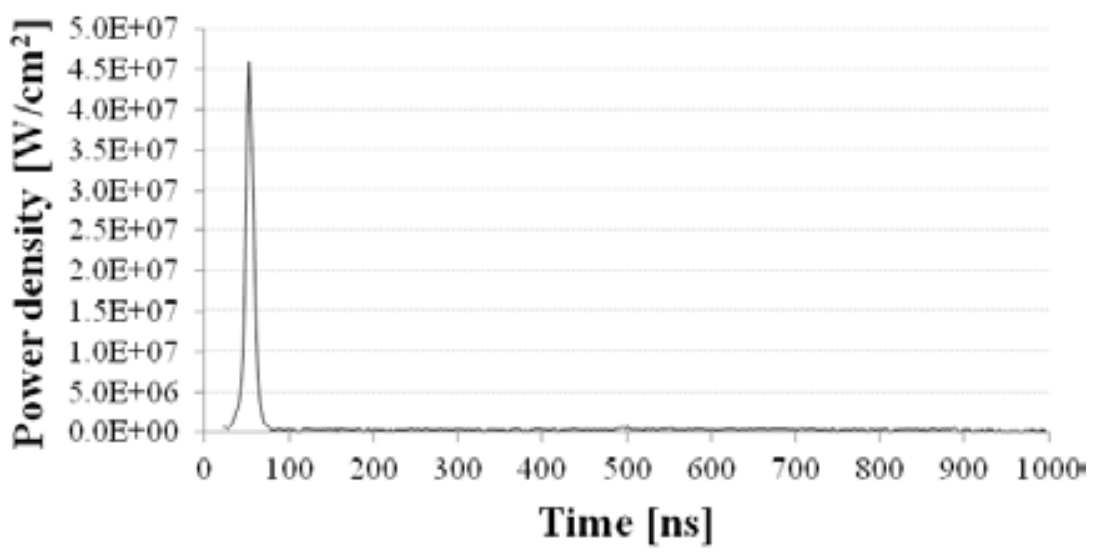

Fig. 1. Time profile of laser power density $(t=0-1000 \mathrm{~ns})$. 


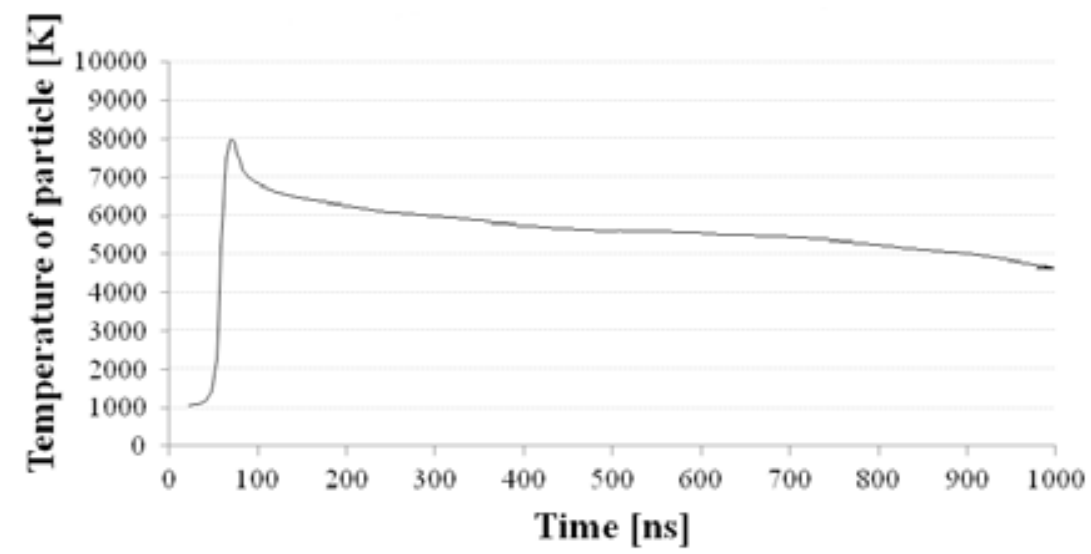

Fig. 2. Time profile of particle temperature $(t=0-1000 \mathrm{~ns})$.

measurement of the intensity time profile data for a pulsed Nd:YAG laser recorded by a streak camera. The specifications of the laser are as follows: pulse energy of $52.8[\mathrm{~mJ} /$ pulse], beam diameter of $2.8 \mathrm{~mm}$, wavelength of $1064 \mathrm{~nm}$, and pulse duration of $8 \mathrm{~ns}$ [full width at half maximum (FWHM)]. The temporal particle diameter was calculated as

$$
D=\left[\frac{6 M}{\pi}\left(\frac{X_{\mathrm{ann}}}{\rho_{\mathrm{a}}}+\frac{X_{\mathrm{melt}}}{\rho_{\mathrm{l}}}+\frac{1-X_{\mathrm{ann}}-X_{\mathrm{melt}}}{\rho_{\mathrm{s}}}\right)\right]^{1 / 3},
$$

where $\rho_{\mathrm{a}}$ is density of the annealed particle given by $\rho_{\mathrm{a}}=2.6-1 \times 10^{-4} \mathrm{~T}\left[\mathrm{~g} / \mathrm{cm}^{3}\right],{ }^{(9)} \rho_{1}$ is the density of liquid carbon given by $\rho_{1}=2.0448-7.0809 \times 10^{-5} T\left[\mathrm{~g} / \mathrm{cm}^{3}\right],{ }^{(9,33)}$ and $\rho_{\mathrm{s}}$ is the density of graphite given by $\rho_{\mathrm{s}}=2.3031-7.3106 \times 10^{-5} T\left[\mathrm{~g} / \mathrm{cm}^{3}\right] \cdot{ }^{(9,33)} X_{\text {ann }}$ and $X_{\text {melt }}$ were estimated to be $1.0 \times 10^{-6}$ in this calculation, ${ }^{(9)}$ and $M$ represents the particle mass.

The particle mass changed during sublimation and during oxidation. The time profile of the particle mass was calculated as

$$
\frac{\mathrm{d} M}{\mathrm{~d} t}=\sum_{j=1}^{10}\left(\frac{\partial M}{\partial t}\right)_{j}+\left(\frac{\partial M}{\partial t}\right)_{\mathrm{ox}}
$$

The first term in the above equation is the rate of mass loss during sublimation. This term is given by

$$
\sum_{j=1}^{10}\left(\frac{\partial M}{\partial t}\right)_{j}=\sum_{j=1}^{10} \frac{-\pi D^{2} W_{j} U_{j} \alpha_{j} B_{j}}{R_{\mathrm{p}} T}
$$


where $W_{j}$ is the molecular weight of a carbon cluster comprising 1-10 carbon atoms with vapor $\left(W_{j}=j \times 12.011 \mathrm{~g} / \mathrm{mol}\right), U_{j}$ is the mean velocity away from the particle surface given by $U_{j}=\left(R_{\mathrm{m}} T / 2 \pi W_{j}\right)^{1 / 2}, R_{\mathrm{m}}$ is the universal gas constant in effective mass units $(8.3145$ $\left.\times 10^{7}\left[\mathrm{~g} \mathrm{~cm}^{2} / \mathrm{mol} \mathrm{K} \mathrm{s}\right]\right)$, and $\alpha_{j}$ is the mass accommodation coefficient of vaporized species. It was assumed that $\alpha_{j}=0.5$ (for $j=1$ and 2), $\alpha_{j}=0.1$ (for $j=3$ ), and $\alpha_{j}=1.0 \times$ $10^{-4}$ (for $j=4$ to 10$){ }^{(9,34)} R_{\mathrm{p}}$ is the universal gas constant in effective pressure units $(82.058$ $\left.\left[\mathrm{atm} \mathrm{cm}^{3} / \mathrm{mol} \mathrm{K}\right]\right) . B_{j}$ is a parameter that represents the effect of diffusive and convective mass and heat transfer during sublimation, given by

$$
\begin{gathered}
B_{j}=\frac{2 D_{\mathrm{eff}} P_{\text {sat }}^{\mathrm{C}_{j}}}{D_{\alpha_{j}} U_{j}+2 D_{\text {eff }}} \text { when } T<3500 \mathrm{~K} \text { at } P_{0}=1 \mathrm{~atm}, \\
B_{j}=\left(P_{\text {sat }}^{\mathrm{C}_{j}}-P_{\text {surf }}^{\mathrm{C}_{j}}\right) \text { when } T>3500 \mathrm{~K} \text { at } P_{0}=1 \mathrm{~atm} .
\end{gathered}
$$

$D_{\text {eff }}$ is the total effective diffusion constant $\left(\mathrm{cm}^{2} / \mathrm{s}\right)$ given by

$$
D_{\text {eff }}=D_{\text {eff }}^{\mathrm{C}_{3}}\left(1-X_{\text {ann }}\right)+D_{\text {eff }}^{\mathrm{C}_{2}} X_{\text {ann }},
$$

and $D_{\text {eff }}^{\mathrm{C}_{j}}$ is the effective diffusion constant of $C_{j}\left(\mathrm{~cm}^{2} / \mathrm{s}\right)$, given by

$$
D_{\text {eff }}^{\mathrm{C}_{j}}=\frac{3 f k_{\mathrm{p}} T}{4 \sigma_{j} P_{0}} \sqrt{\frac{R_{\mathrm{m}}}{\pi W_{j}}} \frac{\left(T+\frac{A_{0}}{A_{1}}\right)^{2}-\left(T_{0}+\frac{A_{0}}{A_{1}}\right)^{2}}{\sqrt{T}\left(T+\frac{3 A_{0}}{A_{1}}\right)-\sqrt{T_{0}}\left(T_{0}+\frac{3 A_{0}}{A_{1}}\right)},
$$

where $f$ is the Eucken factor for the thermal conductivity of a polyatomic gas. ${ }^{(9,35)} f$ is given by

$$
f=\frac{9 \gamma_{j}-5}{4}
$$

where $\gamma_{j}$ is the heat capacity ratio $\left(\gamma_{j}=C_{\mathrm{P}}^{\mathrm{C}_{j}} / C_{\mathrm{V}^{\prime}}^{\mathrm{C}_{j}}\right) ; C_{\mathrm{P}}^{\mathrm{C}_{j}}$ is the heat capacity of $\mathrm{C}_{j}$ at constant pressure. Although each value of $C_{\mathrm{P}}^{\mathrm{C}_{j}}$ (for $j=1$ to 5) can be obtained from a database, ${ }^{(9)}$ $C_{\mathrm{P}^{\mathrm{C}_{j}}}^{\mathrm{C}}$ (for $j=1$ to 10 ) presented here was estimated assuming an asymptotic value of $R(3 j-2){ }^{(9)}$ $C_{\mathrm{V}^{\prime}}^{\mathrm{C}_{j}}$ is the heat capacity of $\mathrm{C}_{j}$ at a constant volume and is calculated as $C_{\mathrm{V}}^{\mathrm{C}_{j}}=C_{\mathrm{P}}^{\mathrm{C}_{j}}-R \cdot{ }^{(9,36)}$

In eq. (40), $k_{\mathrm{p}}$ is the Boltzmann constant in effective pressure units $\left(1.3626 \times 10^{-22}\right.$ $\mathrm{atm} \mathrm{cm} / \mathrm{K})$ and $\sigma_{j}$ is the mean molecular cross section of species $\mathrm{C}_{j}\left(\sigma_{1}=1.2 \times 10^{-15}, \sigma_{2}=\right.$ $2.4 \times 10^{-15}, \sigma_{3}=4.5 \times 10^{-15}, \sigma_{4}=5.6 \times 10^{-15}, \sigma_{5}=7.1 \times 10^{-15}, \sigma_{6}=7.2 \times 10^{-15}, \sigma_{7}=7.0 \times$ $\left.10^{-15}, \sigma_{8}=10.9 \times 10^{-15}, \sigma_{9}=8.7 \times 10^{-15}, \sigma_{10}=9.3 \times 10^{-15} \mathrm{~cm}^{2}\right) \cdot{ }^{(9)} A_{0}$ and $A_{1}$ in eq. (40) are constants that express the thermal conductivity of the gas $(\mathrm{W} / \mathrm{cm} \mathrm{K}):{ }^{(9)} A_{0}=9.0235 \times 10^{-4}$, $A_{1}=3.8475 \times 10^{-7}$ (for $i=2$ ), and $A_{0}=5.7683 \times 10^{-4}, A_{1}=1.8429 \times 10^{-7}$ (for $i=3$ ).

$P_{\text {sat }}^{\mathrm{C}_{j}}$ in eqs. (37) and (38) is the saturation partial pressure of $\mathrm{C}_{j}(\mathrm{~atm})$, given by 


$$
\begin{gathered}
\Delta S_{j}=b_{S 0}+b_{S 1} T+b_{S 2} T^{2}, \\
\Delta H_{j}=b_{H 0}+b_{H 1} T+b_{H 2} T^{2} .
\end{gathered}
$$

The coefficients in eqs. (42) and (43) are given in Table 2. These values are based on Michelsen's work, ${ }^{(9)}$ who derived them from a previous study ${ }^{(19)}$ by fitting the data using a quadratic equation.

The second term of eq. (35) is given by

$$
\left(\frac{\partial M}{\partial t}\right)_{\mathrm{ox}}=-\frac{2 \pi D^{2} W_{1} k_{\mathrm{ox}}}{N_{\mathrm{a}}},
$$

where $N_{\mathrm{a}}$ is Avogadro's constant and the overall rate for oxidation $k_{\mathrm{ox}}$ was used to represent the oxidation process. Figure 3 illustrates the time profile of particle diameter. The initial particle diameter was assumed to be $25-50 \mathrm{~nm}$ and the ambient temperature was assumed to be $1060 \mathrm{~K}$ for the analysis of soot in the flame of a candle.

The LII time profile was calculated by substituting the particle temperature into eq. (10). Figures 4-6 illustrate comparisons of the normalized LII signals for a laser intensity profile and for particle size prediction using the above calculations. These graphs indicate that the particles with larger diameters are characterized by extended thermal emission.

As illustrated in Figs. 4-6, a single logarithmic plot for intensity provides sufficient resolution for the determination of particle diameter. Thus, using the Stefan-Boltzmann law for a blackbody, the LII signal produces a profile of the intensity decay time that depends on the measured wavelength and particle size.

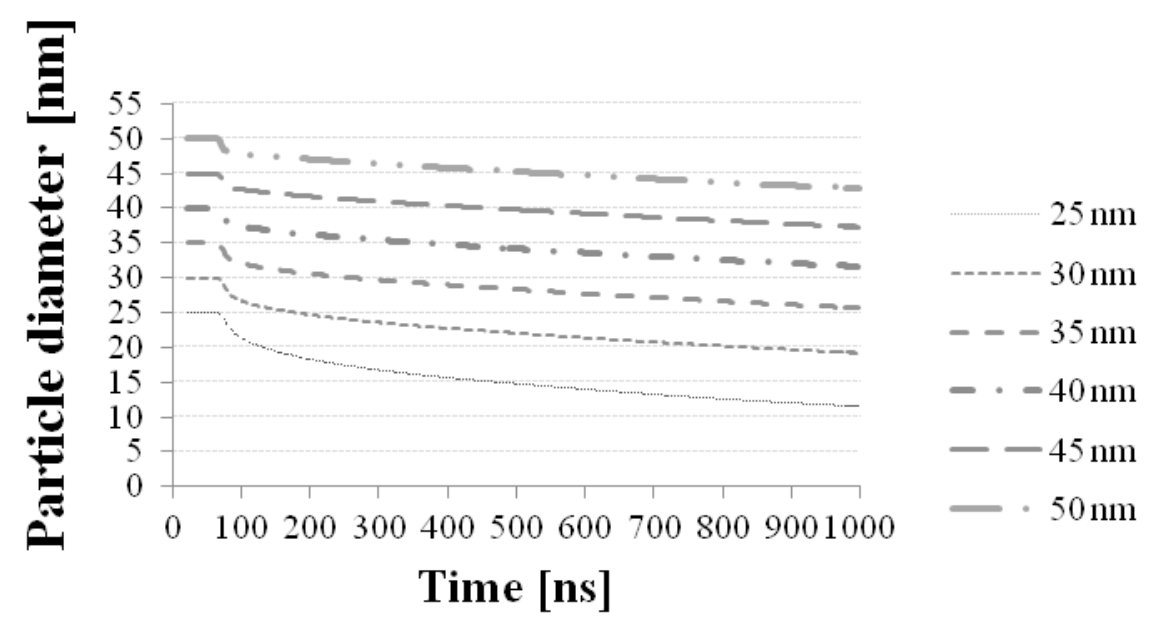

Fig. 3. Time profile of particle diameter $(t=0-1000 \mathrm{~ns})$. 


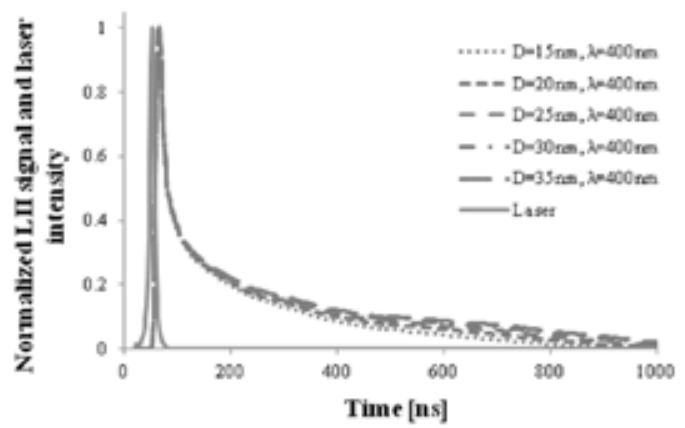

(a)

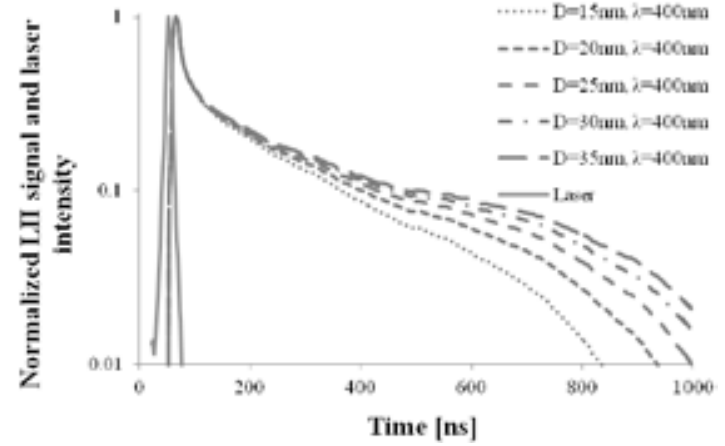

(b)

Fig. 4. Comparison of a normalized laser profile with the LII-calculated profile at a wavelength of $400 \mathrm{~nm}(t=0-1000 \mathrm{~ns})$ : (a) normal plot and (b) single logarithmic plot.

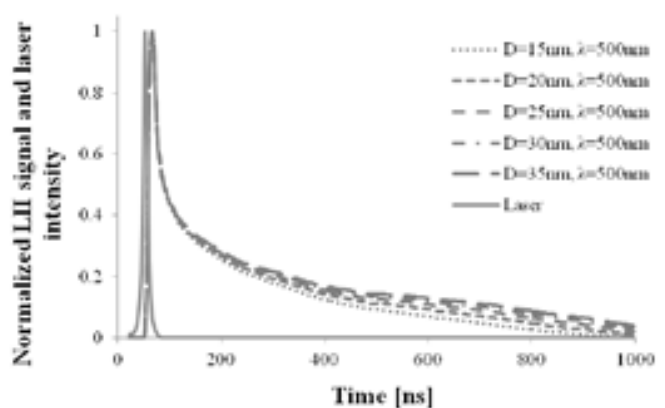

(a)

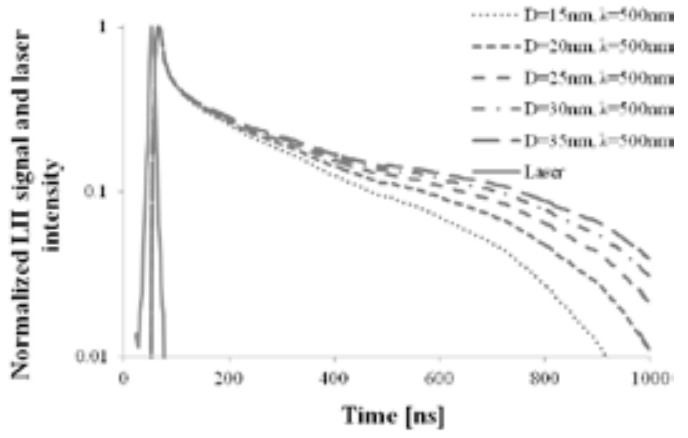

(b)

Fig. 5. Comparison of a normalized laser profile with the LII-calculated profile at a wavelength of $500 \mathrm{~nm}(t=0-1000 \mathrm{~ns})$ : (a) normal plot and (b) single logarithmic plot.

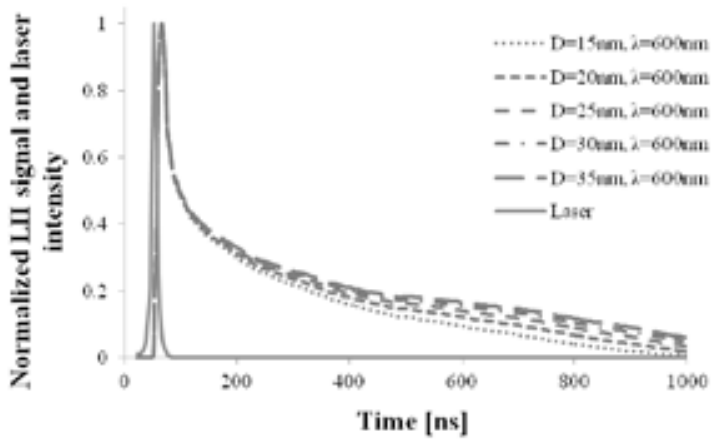

(a)

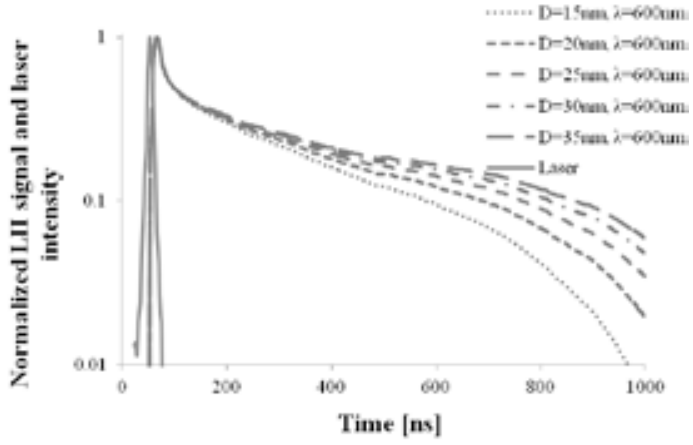

(b)

Fig. 6. Comparison of a normalized laser profile with the LII-calculated profile at a wavelength of $600 \mathrm{~nm}(t=0-1000 \mathrm{~ns})$ : (a) normal plot and (b) single logarithmic plot. 


\section{Experiments}

Figure 7 illustrates a schematic of the LII and LIBS system. The optical layout of the LII and LIBS system consists of four subsystems: a Nd:YAG laser, a spectrograph, a streak camera, and a delay pulse generator. The laser was operated at $1064 \mathrm{~nm}$ to generate a $52.8 \mathrm{~mJ}$ Q-switched pulse with a width of $8 \mathrm{~ns}$ (FWHM). The emissions from the target were guided into the spectrograph and dispersed by a grating with a groove density of 1200 lines $/ \mathrm{mm}$, and the resulting electrical signal was recorded using a streak camera. The data were stored in a computer. Both the LII and LIBS techniques are based on analysis of the cooling behavior of the particles after irradiation by the laser pulse. A comparison of the intended uses of the devices for LII and LIBS is shown in Table 3.

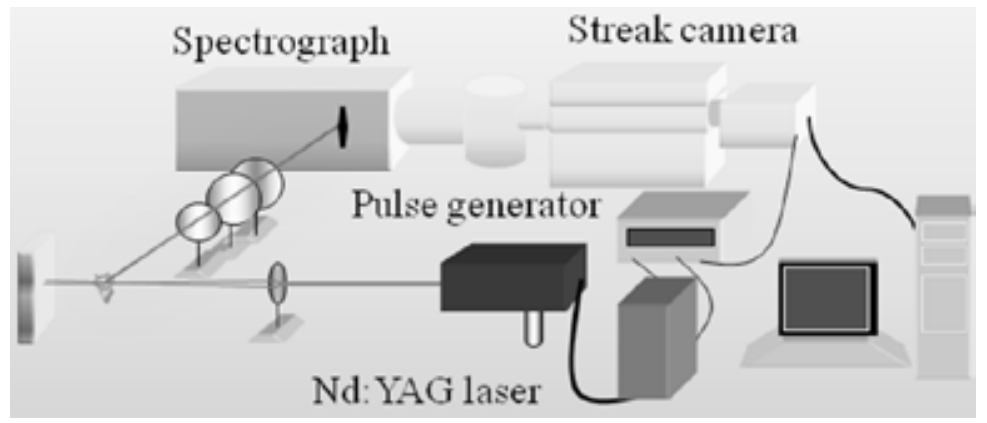

Fig. 7. Schematic of combined system for LII and LIBS analyses.

Table 3

Comparison of intended use of the devices for LII and LIBS analyses.

\begin{tabular}{|c|c|c|}
\hline & LII & LIBS \\
\hline $\begin{array}{l}\text { Delay/pulse generator } \\
\text { (DG535, Stanford Research } \\
\text { Systems, INC.) }\end{array}$ & $\begin{array}{l}{ }^{*} 185-285 \mu \text { s for Q-SW open } \\
{ }^{*} 184.5-185.5 \mu \text { s for streak camera } \\
\text { shutter open }(1000 \text { ns gate time })\end{array}$ & $\begin{array}{l}{ }^{*} 185-285 \mu \text { for } \mathrm{Q}-\mathrm{SW} \text { open } \\
{ }^{*} 179-199 \mu \text { s for streak camera } \\
\text { shutter open }(20 \mu \text { s gate time }) \\
\end{array}$ \\
\hline $\begin{array}{l}\text { Nd:YAG laser } \\
\text { (ULTRA CFR, Big Sky Laser) } \\
\text { ( } 8 \mathrm{~ns}, \lambda=1064 \mathrm{~nm}, 50 \mathrm{~mJ} / \text { pulse } \\
\text { at maximum output) }\end{array}$ & $\begin{array}{l}\text { Heating } \\
0.6-25 \mathrm{~mJ} / \text { pulse } \\
10^{7}-10^{9} \mathrm{~W} / \mathrm{cm}^{2} \text { at peak power } \\
\text { density (adjustment to avoid } \\
\text { plasma generation) }\end{array}$ & $\begin{array}{l}\text { Plasma generation } \\
25-50 \mathrm{~mJ} / \text { pulse } \\
\text { Minimum peak power density } \\
\text { with a condenser lens } \\
10^{11}-10^{12} \mathrm{~W} / \mathrm{cm}^{2} \text { (for gas) } \\
10^{10}-10^{11} \mathrm{~W} / \mathrm{cm}^{2} \text { (for liquid) } \\
10^{9}-10^{10} \mathrm{~W} / \mathrm{cm}^{2} \text { (for solid) }\end{array}$ \\
\hline $\begin{array}{l}\text { Condenser lens } \\
(f=50 \mathrm{~mm}, \varnothing=25 \mathrm{~mm})\end{array}$ & Non use & Use \\
\hline $\begin{array}{l}\text { Spectrograph } \\
(250 \text { is, CHROMEX) }\end{array}$ & $\begin{array}{l}\text { For the selection of measuring } \\
\text { wavelength }\end{array}$ & $\begin{array}{l}\text { For dispersing plasma emission to } \\
\text { obtain spectroscopic data }\end{array}$ \\
\hline $\begin{array}{l}\text { Streak camera } \\
\text { (C5680+M5677, C4742, } \\
\text { HAMAMATSU Photonics) }\end{array}$ & $\begin{array}{l}\text { To obtain time profile of cooling } \\
\text { behavior of particles }\end{array}$ & $\begin{array}{l}\text { For observation by separating } \\
\text { excitation relaxation light from } \\
\text { bremsstrahlung }\end{array}$ \\
\hline
\end{tabular}




\section{Results}

Here, the experimental results of the LII and LIBS measurements of soot in a candle are shown. The size evaluation was carried out using the LII technique, while atomic signals of carbon were obtained using the LIBS technique with the same measurement system. Candle soot is thought to consist of particles of a few tens of nanometers in diameter. The larger agglomerates tend to be rich in partially pyrolyzed wax. The formation of these agglomerates is largely the result of convection and turbulent airflow around the wick. The oxygen in the air is quickly consumed by the hydrogen from the wax molecules and any residual oxygen is then available to combine with the carbon to form carbon dioxide. Providing more air tends to grow the wax vapor and the unconsumed carbon residues in the flame toward the cooler environment of the room away from the flame. The unconsumed carbon residues in the flame indicate that the wax condenses around the carbon particles, and the particles stick together to form large agglomerates. The combined LII and LIBS system will help elucidate the role of the oxygen density and the hydrocarbon content in wax in the soot agglomeration process.

\subsection{LIBS measurements}

Figure 8 is an example of atomic signals obtained from LIBS measurements using 100 laser pulses for soot in a candle flame. Seven measurements were conducted to obtain the spectrum at a wavelength of $247.856 \mathrm{~nm}$. The spectrum covers the range over which the electron transits from excitation to relaxation, as shown in eq. (7). Figure 9 illustrates the time profile of carbon plasma $(\lambda=247.856 \mathrm{~nm})$.

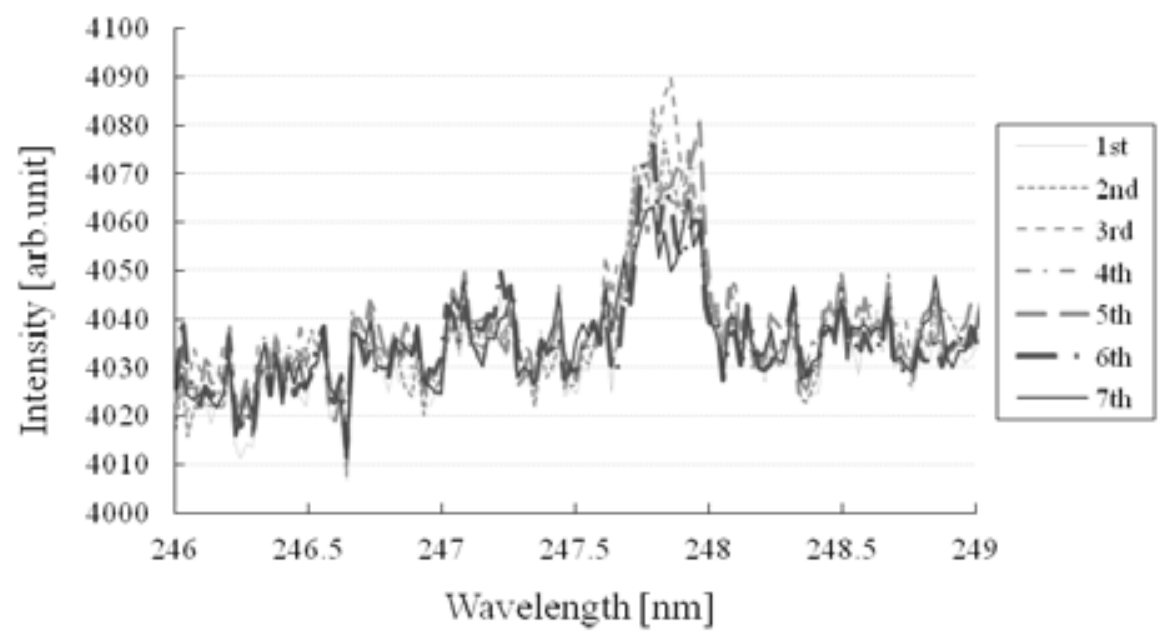

Fig. 8. Variation in the carbon emission intensity at wavelength $\lambda=247.856 \mathrm{~nm}$ obtained from seven LIBS measurements using 100 laser pulses and a $20 \mu$ s gate setting for soot in a candle flame. 


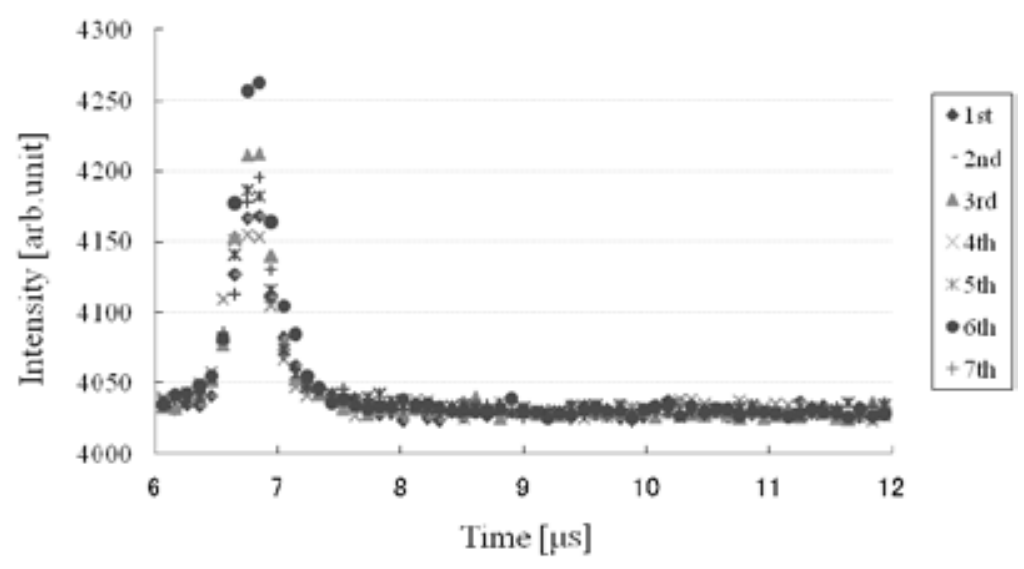

Fig. 9. Time profile of carbon plasma and atomic spectrum emission intensity at wavelength $\lambda=$ 247.856 .

Different spectral peaks were obtained in the LIBS measurement for carbonaceous materials such as charcoal when the spectra were recorded at wavelengths of (a) 279.05 , (b) 279.67 , (c) 283.67 , (d) 358.0 , (e) 385.59, (f) 386.41, (g) 387.57, (h) 392.71, (i) 396.19, and (j) $422.0 \mathrm{~nm}$. However, even though wavelength calibration was conducted, some of these spectra do not correspond entirely to the carbon atomic spectra on the NIST database. For example, observable spectra of carbon depend on the chemical bonding state, as shown in Fig. 10. In fact, these spectra could be explained by a hypothesis based on other spectroscopic effects.

\subsection{LII measurements}

Figure 11 illustrates an example of the comparison of the normalized LII signal for an experimental result and for particle size predictions using the above calculations. The LII signal was obtained using 1000 laser pulses and a 1000 ns gate setting for soot in a candle flame. The results recorded using the LII technique indicate that the particle diameter was about $15-20 \mathrm{~nm}$.

\section{Discussion}

In previous research, the diameters of primary particles of soot were estimated to be 10-40, ${ }^{(37)} 30-51,{ }^{(38)} 32,{ }^{(39)}$ and $20 \mathrm{~nm} .{ }^{(40)}$ According to di Stasio, ${ }^{(41)}$ carbon nanoparticles can be separated into three classes. The first is recognized as a class of primary particles $(20-50 \mathrm{~nm})$ that are usually reported to be subunits that make up chainlike and fractal soot aggregates. The other two categories are known as subprimary graphitic particles (6-9 $\mathrm{nm}$ ) and elementary particles (less than $5 \mathrm{~nm}$ ), based on measurement using a transmission electron microscope (TEM). Thus, the particle diameter of soot measured in this study is in good agreement with previous estimates of primary particle diameter. 


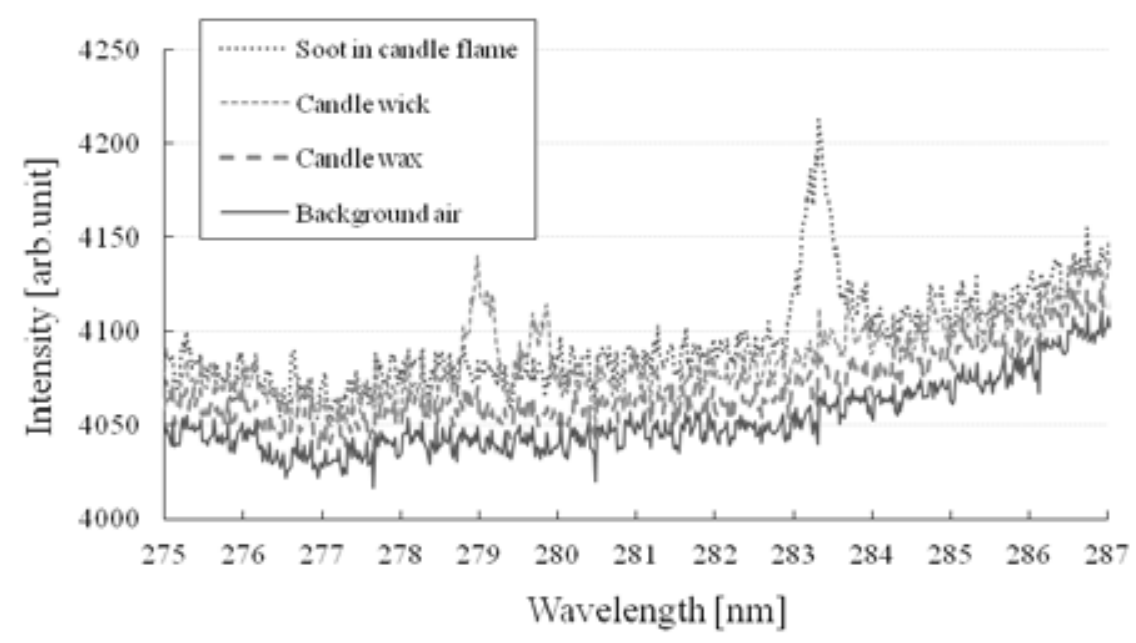

Fig. 10. LIBS signals obtained from carbonaceous materials and background air at wavelengths of $275-287 \mathrm{~nm}$.

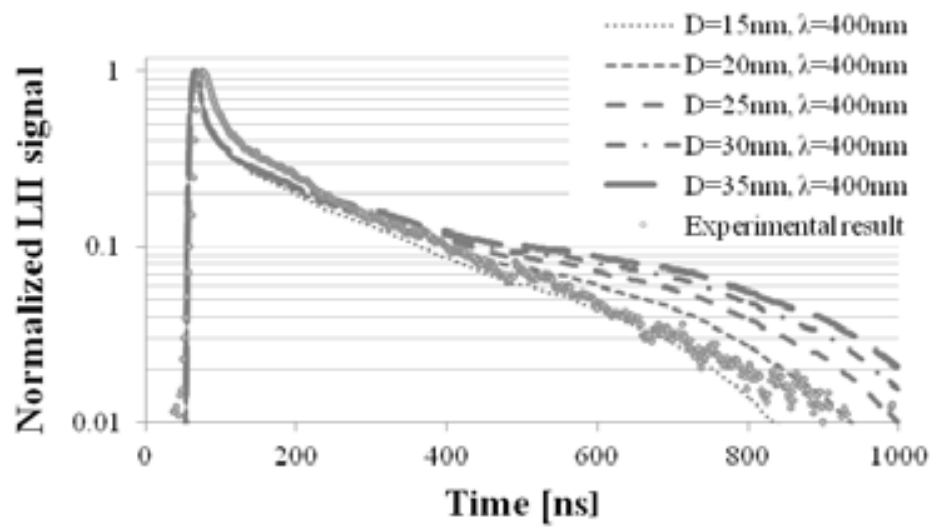

Fig. 11. Comparison of a normalized LII calculated profile with the experimental profile obtained for a carbon particle at a wavelength of $400 \mathrm{~nm}$.

\section{Conclusions}

Elemental composition analysis using LIBS and particle size measurements using LII were successfully accomplished by implementing a system that combined both techniques. The combined system generates a powerful synergy effect for fine-particle 
measurement. In the LII measurements, the choice of excitation wavelength was determined mainly to avoid the creation of photochemical interference. Disagreement between the time profiles of the experimental results and calculation values indicates that neglecting primary soot aggregation causes some potential error in addition to the uncertainties in the absorption coefficient and emissivity. The experimental data are based on signal-averaged values obtained from 1000 laser shots. The results presented here do not include any particle size distribution data. However, the application of several averaging processes should allow the LII technique to be used to obtain particle size distributions. The fluctuations in LII measurements make it difficult to conduct LII measurements in unsteady combustion; thus, we have been limited to pointwise detection in this study. LII plays an important role in the analysis of average primary particle sizes in a combustion flame. Furthermore, particle size calibration for LII could potentially improve the agreement with the LII signal for standard carbon particles.

\section{Acknowledgments}

Part of this study resulted from research performed under Waseda University Grants for Special Research Projects (2010A-907 and 2011B-238).

\section{References}

1 J. H. Brown, K. M. Cook, F. G. Ney and T. Hatch: AJPH 40 (1950) 450.

2 U. P. Kodavanti, M. C. Schladweiler, A. D. Ledbetter, W. P. Watkinson, M. J. Campen, D. W. Winsett, J. R. Richards, K. M. Crissman, G. E. Hatch and D. L. Costa: Toxicol. Appl. Pharmacol. 164 (2000) 250.

3 G. L. Squadrito, C. Rafael, B. Dellinger and W. A. Pryor: Free Rad. Biol. Med. 31 (2001) 1132.

4 A. P. Carll, N. Haykal-Coates, D. W. Winsett, W. H. Rowan III, M. S. Hazari, A. D. Ledbetter, A. Nyska, W. E. Cascio, W. P. Watkinson, D. L. Costa and A. K. Farraj: Inhalation Toxicol. 22 (2010) 355.

5 M. Wakamatsu, S. Ikezawa and T. Ueda: IEEJ Trans. Sens. Micromach. 127 (2007) 397.

6 A. C. Eckbreth: J. Appl. Phys. 48 (1977) 4473.

7 L. A. Melton: Appl. Opt. 23 (1984) 2201.

8 T. P. Jenkins, J. L. Bartholomew, P. A. DeBarber, P. Yang, J. M. Seitzman and R. P. Howard: Proc. 40th AIAA Aerospace Sciences Meeting (AIAA, Reston, VA, USA, 2002) 2002-0828.

9 H. A. Michelsen: J. Chem. Phys. 118 (2003) 7012.

10 E. W. Van Stryland, M. J. Soileau, A. L. Smirl and W. E. Williams: Phys. Rev. B 23 (1981) 2144.

11 P. K. Bandyopadhyay and L. D. Merkle: J. Appl. Phys. 63 (1988) 1392.

12 A. M. Bonch-Bruevich and V. A. Khodovoi: Sov. Phys. Usp. 85 (1965) 3.

13 A. M. Malvezzi and M. Romanoni: Int. J. Thermophys. 13 (1992) 131.

14 D. L. Greenaway, G. Harbeke, F. Bassani and E. Tosatti: Phys. Rev. 178 (1969) 1340.

15 B. J. Stagg and T. T. Charalampopoulos: Combust. Flame 94 (1993) 381.

16 A. Borghesi and G. Guizzetti: Handbook of Optical Constants of Solids II, ed. E. D. Palik (Academic, San Diego, 1998) p. 449.

17 B. J. McCoy and C. Y. Cha: Chem. Eng. Sci. 29 (1974) 381. 
18 R. C. Weast: Handbook of Chemistry and Physics (Chemical Rubber Company, West Palm Beach, FL, 1978).

19 M. W. Chase, Jr., C. A. Davies, J. R. Downey, Jr., D. J. Frurip, R. A. McDonald and A. N. Syverud: J. Phys. Chem. Ref. Data Suppl. 14 (1985) 1.

20 F. Ames, M. Dobeli, C. R. Musil, P. W. Nebiker, L. Scandella, M. Suter and H. A. Synal: Nucl. Instrum. Methods Phys. Res. B 112 (1996) 64.

21 C. H. Wu, U. Mszanowski and J. M. L. Martin: J. Nucl. Mater. 258-263 (1998) 782.

22 S. Arepalli, C. D. Scott, P. Nikolaev and R. E. Smalley: Chem. Phys. Lett. 320 (2000) 26.

23 E. Vietzke, A. Refke, V. Philipps and M. Hennes: J. Nucl. Mater. 241-243 (1997) 810.

24 V. Philipps, E. Vietzke and K. Flaskamp: Surf. Sci. 178 (1986) 806.

25 L. Brewer and J. S. Kane: J. Phys. Chem. 59 (1955) 105.

26 V. I. Bukatyi, E. P. Zhdanov and A. M. Shaiduk: Combustion, Explosion, and Shock Waves, Vol. 18, No. 3 (Springer, New York, 1982) p. 309.

27 T. J. Konno and R. Sinclair: Acta Metall. Mater. 43 (1995) 471.

28 P. A. Marcos, M. J. López, A. Rubio and J. A. Alonso: Chem. Phys. Lett. 273 (1997) 367.

29 G. G. Samsonidze, G. G. Samsonidze and B. I. Yakobson: Phys. Rev. Lett. 88 (2002) 065501-1.

30 F. Banhart, T. Füller, Ph. Redlich and P. M. Ajayan: Chem. Phys. Lett. 269 (1997) 349.

31 B.-C. Wang, H.-W. Wang, J.-C. Chang, H.-C. Tso and Y.-M. Chou: J. Mol. Struct. THEOCHEM 540 (2001) 171.

32 F. Atamny, J. Bloecker, B. Henschke, R. Schloegl, T. Schedel-Niedrig, M. Keil and A. M. Bradshaw: J. Phys. Chem. 96 (1992) 4522.

33 L. E. Fried and W. M. Howard: Phys. Rev. B 61 (2000) 8734.

34 L. Brewer and J. S. Kane: J. Phys. Chem. 59 (1955) 105.

35 E. R. G. Eckert and R. M. Drake, Jr.: Analysis of Heat and Mass Transfer (McGraw-Hill, New York, 1972).

36 P. W. Atkins: Physical Chemistry, 4th ed. (Freeman, New York, 1990).

37 C. M. Megridis and R. A. Dobbins: Int. Symp. Combust. 22 (1989) 353.

38 Ü. Ö. Köylü and G. M. Faeth: Combust. Flame 89 (1992) 140.

39 Ü. Ö. Köylü, G. M. Faeth, T. L. Farias and M. G. Carvalho: Combust. Flame 100 (1995) 621.

40 R. L. Vander Wal and M. Y. Choi: Carbon 37 (1999) 231.

41 S. di Stasio: Carbon 39 (2001) 109. 